\title{
Vascularized Bone Graft Reconstruction Following Bone Tumor Resection at a Multidisciplinary Sarcoma Center: Outcome Analysis
}

\author{
SABINA M. GORSKI ${ }^{1,2}$, CHAO DONG $^{1,3}$, ANDREAS. H. KRIEG ${ }^{1,3^{*}}$ and MARTIN HAUG ${ }^{2,3 *}$ \\ ${ }^{1}$ Paediatric Orthopaedic Department, University Children's Hospital (UKBB), Basel, Switzerland; \\ ${ }^{2}$ Departement of Plastic, Reconstructive \& Aesthetic Surgery and Hand Surgery, \\ University Hospital, Basel, Switzerland; \\ ${ }^{3}$ Bone and Soft Tissue Tumor Center (KWUB), University Hospital, Basel, Switzerland
}

\begin{abstract}
Background/Aim: Limb-sparing procedures are frequently applied to improve patient outcomes. The use of vascularized bone grafts is associated with significant improvements in oncologic safety and functional satisfaction. This study highlights the clinical outcomes following tumor resection combined with vascularized bone graft reconstructions. Patients and Methods: Twenty-five free vascularized bone grafts (17 fibulas, 5 iliac crests, 3 medial femoral condyles) were assessed with respect to consolidation and hypertrophy, functional and oncologic outcomes, and local complications. Results: The rate of healing of fibular grafts after a median of 5 months was $86 \%$. The rate of achieved unions of iliac crest grafts after a median of 5 months was $80 \%$. In medial femoral condyle bone grafts, union occurred after a median of 4 months. Significant hypertrophy was observed in 13 patients. We identified six complications with highest rates in the fibulagroup. Despite the high complications, functional results were highly satisfactory. Conclusion: Vascularized bone grafts represent a reconstructive approach, maintaining long-term functionality and cosmetic satisfaction without compromising tumor recurrence outcomes.
\end{abstract}

With an estimated annual incidence rate of 0.8 cases per 100,000 individuals, bone sarcomas represent a rare tumor

This article is freely accessible online.

*These Authors contributed equally to this work.

Correspondence to: Sabina M. Gorski, University Hospital, Spitalstrasse 21, CH-4031 Basel, Switzerland. Tel: +41 612652525, e-mail: sabina.gorski@usb.ch

Key Words: Bone sarcoma, fibula, iliac crest, medial femoral condyle, limb-sparing procedure, vascularized bone graft, vascularized bone graft reconstruction. entity (1). Among children aged 0-14 years, however, bone sarcomas account for approximately 4-6\% of all childhood malignancies (2). Since prognosis has improved for bone tumor patients, surgical interventions have changed towards limb-sparing procedures that maintain oncologic safety in combination with function and appearance $(3,4)$. Various reconstructive procedures have been developed, including allografts $(5-7)$, autografts using non-vascularized $(8,9)$ or vascularized tissues (10-12), and tumor endoprostheses (13, 14). According to oncological guidelines, the decision on whether a surgical intervention is indicated should be carefully evaluated on a case-by-case basis in an interdisciplinary tumor board, and biological reconstruction should be preferred in children, adolescents, and young adults.

The use of non-vascularized bone grafts has been the mainstay in biological reconstruction. This approach does not require microsurgical expertise, and clinical advantages include shorter operative time, low complication rates, and the possibility of remodeling at the donor site $(8,9)$. In practice, similar outcomes can be achieved with both vascularized and non-vascularized bone grafts for reconstruction of segmental bone defects following diaphyseal tumor resection (15). In the decision to vascularize a graft, the length of the defect is an important factor to consider in order to avoid graft failure and revision surgery. Lenze et al. revealed that the use of nonvascularized bone grafts is especially recommended to segmental defects of less than $12 \mathrm{~cm}$ in which no concomitant use of chemotherapy is required (9).

Tumor excision often results in extensive bone defects and, in cases where bone tumors are close to the cartilage surface, in secondary joint lesions. These factors are a constant challenge for surgeons to ensure structural integrity and mechanical strength, particularly near joints and in areas of high biomechanical load. Vascularized bone grafts are deemed to represent the best reconstructive approach in cases with significant bone loss in which amputation may be the 
only alternative. The first bone transfer using a free vascularized fibular graft to reconstruct a tibial defect in two trauma cases was described by Taylor et al. in 1975 (16), and over the years, several studies have also shown its significant success in patients following bone tumor resection (10-12). However, prior reviews are generally focused on one specific bone graft, and only few have compared the various available bone graft options. Therefore, the aim of this study was to examine and compare clinical outcomes of bone tumor patients who had undergone microsurgical bone transposition using the ipsilateral fibula, iliac crest, or medial femoral condyle by means of a quality outcome analysis comparing radiographic outcome in terms of consolidation and hypertrophy, functional as well as oncologic outcomes, and local complications at the donor and recipient sites.

\section{Patients and Methods}

Between 2000 and 2019, 26 patients affected by malignant or aggressive bone tumors at the extremities have undergone microvascular reconstruction at our institution, 15 males and 11 females, with a mean age of 17.4 years (ranged=3-39 years) at the time of definitive tumor surgery. We excluded one case in which a total replacement by tumor endoprosthesis was performed briefly after index surgery. An Ewing's sarcoma was present in seven cases, an osteosarcoma in six patients, a giant cell tumor in four patients, a chondroblastoma in three patients, an adamantinoma in two patients, and a chondrosarcoma, an aneurysmal bone cyst and a rhabdomyosarcoma attached to the tibial bone in one case each. Affected sites were the femur [9], tibia [8], talus [4], humerus [2], and radius [2]. Surgical reconstruction was performed with a vascularized fibular graft (Figure 1) in seventeen cases, with an iliac crest graft (Figure 2) in five cases, and with a medial femoral condyle graft in three cases. The mean defect size was $12.9 \mathrm{~cm}$, ranging from 2 to $28 \mathrm{~cm}$; the mean length of the harvested fibula grafts, iliac crest grafts, and medial femoral condyle grafts were $16.7 \mathrm{~cm}, 5.0 \mathrm{~cm}$, and $2.8 \mathrm{~cm}$, respectively. The method of fixation was plates in seventeen cases, screws in three cases, plates and screws in two cases, and Kirschner wires with screws in one patient. In two patients, only pressfit without fixation was possible.

After surgery, all patients were regularly followed-up at our oncological orthopedic outpatient clinic every six to twelve weeks until complete consolidation was achieved. The median follow-up period was 6.7 years with an interquartile range of 1.2-14.3 years. Plain radiographs were evaluated for bony union, hypertrophy, local recurrence, and complications. Bony union was defined as a complete osseous consolidation at both osteotomy sites within twelve months after surgery. Delayed union was considered as incomplete consolidation after twelve months, whereas non-union was assumed after twenty-four months. Major advantage of vascularized bone grafts over conventional bone grafts is the ability to hypertrophy resulting in increased mechanical strength. We defined this structural change as biological activity, represented by an increase in diameter at the graft-host junctions, and measured biological activity according to De Boer and Wood's study (17). Therefore, hypertrophy was considered significant if the hypertrophy index increased by more than $20 \%$. A hypertrophy index between 0 and $20 \%$ was defined as a biological active graft without significant hypertrophy. An index of $0 \%$ or lower was considered to indicate an atrophic graft (8).

The Musculoskeletal Tumour Society (MSTS) Score (18) was used to evaluate patients' functional outcomes. A score of $86-100 \%$ was considered as excellent, $70-85 \%$ as good, $50-69 \%$ as satisfactory, and $0-49 \%$ as a poor functional result.

Additional treatments (chemotherapy, radiotherapy, extracorporeal irradiation) as well as any donor/host site complications requiring surgical intervention were recorded according to Henderson classification (19).

Statistical analysis. We performed all analyses using SPSS software, version 23.0 (SPSS Inc., Chicago, IL, USA). Data are expressed as medians with interquartile ranges (IQR) and as means with standard deviations (SD) for continuous endpoints. Binary endpoints were assessed using absolute and relative numbers of patients and grafts. Fisher's exact test and two-sample Wilcoxon test were performed to evaluate paired data. All tests were performed at a significance level of $\alpha=0.05$.

The study was approved by the local ethical committee (Ethikkomission Nordwest und Zentralschweiz, number: 201900212), and the criteria of the Declaration of Helsinki were followed.

\section{Results}

Clinical findings. Patient characteristics are shown in Table I. Fourteen patients (56\%) received neo-/adjuvant treatment according to the EURAMOS-1, EURO-B.O.S.S., or EUROE.W.I.N.G. 99 protocol. In one patient adjuvant chemotherapy was applied in combination with radiotherapy. Six patients $(24 \%)$ were treated with extracorporeal irradiation (50 Gy). R0-resection was achieved in 24 patients (96\%), while one patient underwent R1-resection. Four patients $(16 \%)$ developed local tumor recurrence; no patient died as a result of the oncologic disease.

Consolidation. The harvested fibula had a mean length of $16.7 \mathrm{~cm}$ (range $=8-27.5 \mathrm{~cm}$ ) and was used to bridge defects with a mean length of $16 \mathrm{~cm}$ (range $=7-28 \mathrm{~cm}$ ). Bony union was evaluated in 14 patients (those excluded were two patients from abroad and one patient who underwent hemipelvectomy for local tumor recurrence). Complete bony union (<12 months) was observed in $86 \%(12 / 14)$ of patients at the proximal osteotomy sites, after a median (IQR) time of 5 (3-12) months, and in 64\% (9/14) of patients at the distal osteotomy site after a median (IQR) of 6 (3-12) months. Delayed union occurred in one proximal and five distal junctions but healed at a median (IQR) of 18 (13-30) months. Therefore, the vascularized fibular grafts had achieved overall bony union at a median (IQR) of 6 (4-12) months in 13 out of 14 patients; the remaining was a case of nonunion at the proximal end of the fibular graft.

The vascularized iliac crest graft was selected in five patients. The iliac crest grafts had a mean length of $5.0 \mathrm{~cm}$ (range $=2.8-6.5 \mathrm{~cm}$ ) to bridge defects with a mean length of 


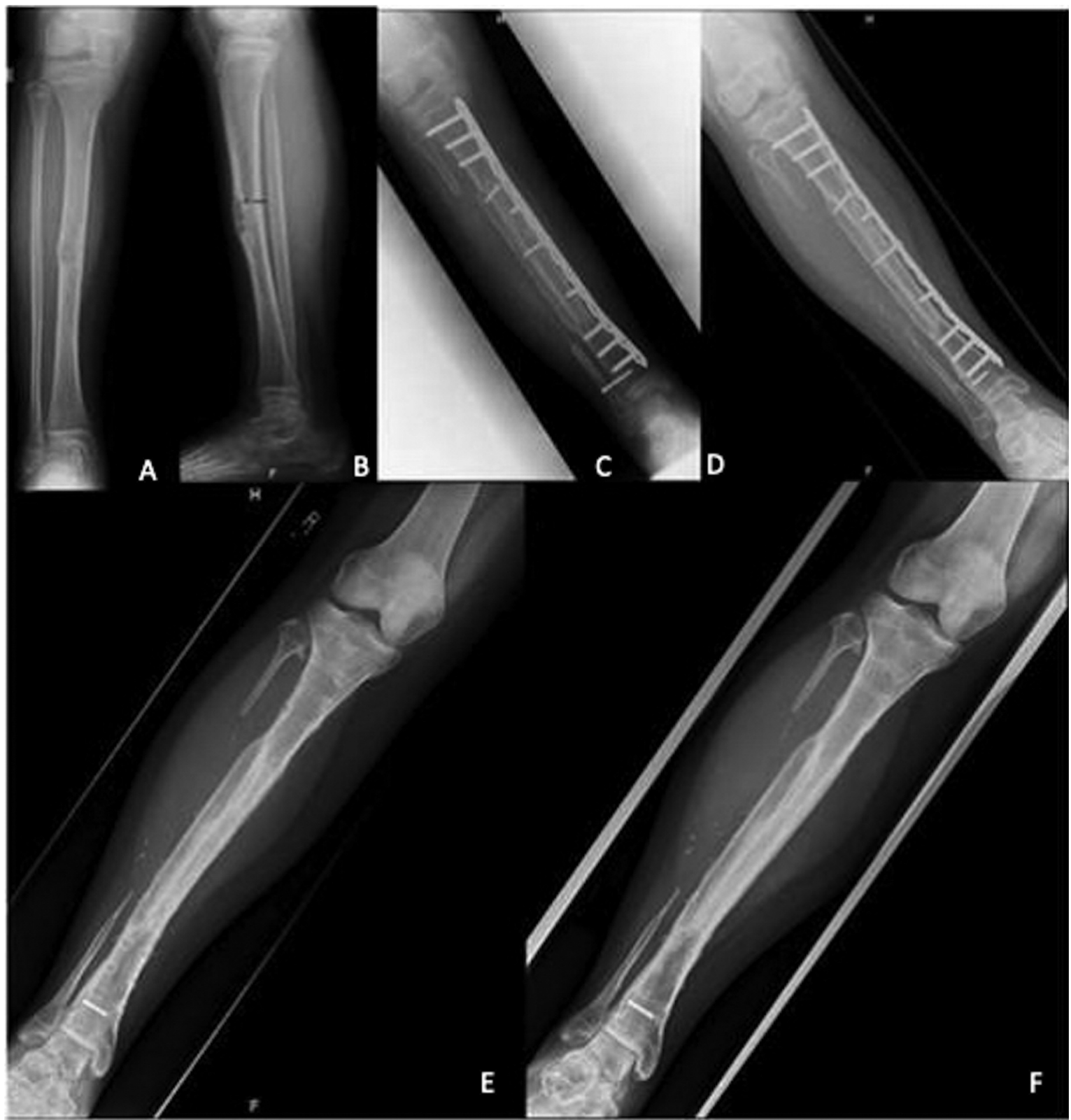

Figure 1. An 11-year-old female patient with an adamantinoma of the right tibia. Preoperative conventional X-rays anteroposterior view (A) and lateral view (B). Postoperative conventional X-rays 3 months after segmental resection $(C)$. The graft was fully integrated 6 months after surgery (D). Plate removal was performed 5 years after the initial surgery $(E)$. Postoperative imaging at 10 years follow-up appointment $(F)$.

$4.8 \mathrm{~cm}$ (range $=3-7 \mathrm{~cm})$. Bony union was achieved primarily in $80 \%(4 / 5)$ of the patients after a median (IQR) time of 5 (3-12) months. One patient showed delayed union, which healed after 18 months.

The medial femoral condyle bone grafts were used to bridge talar defects with a mean length of $2.5 \mathrm{~cm}$ (range $=2$ $3.4 \mathrm{~cm}$ ). The medial femoral condyle bone graft had a mean length of $2.8 \mathrm{~cm}$ (range $=2-3.5 \mathrm{~cm}$ ) and was used in 3 patients. Complete bony union was observed primarily in all three patients at a median (IQR) time of 4 (4-12) months.

Biological activity and hypertrophy. Once complete bony union was achieved, biological activity was observed in $70 \%$ of the junctions. Significant hypertrophy of more than $20 \%$ 


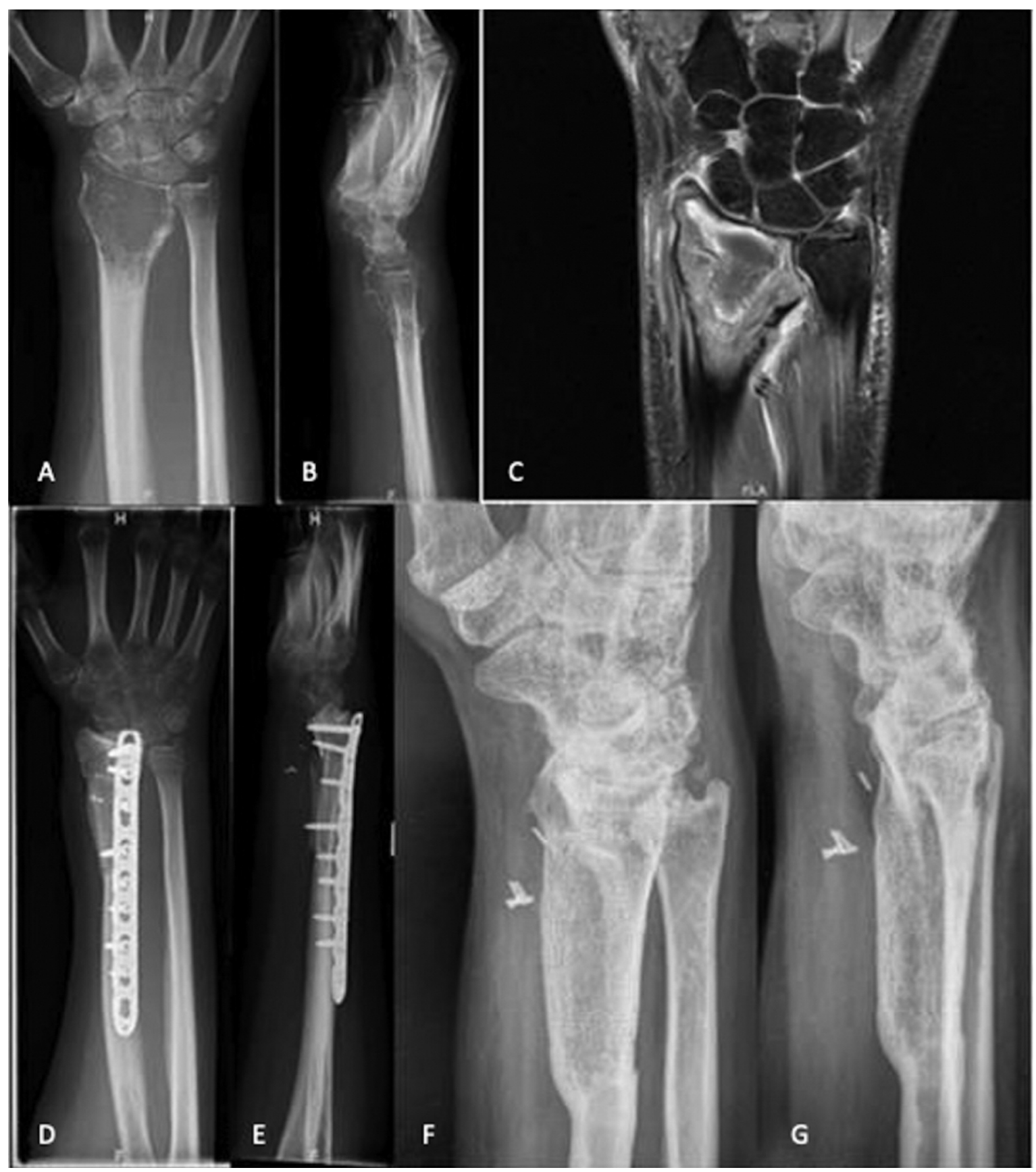

Figure 2. A 31-year-old female patient with a giant cell tumor of the right distal radius: preoperative conventional X-rays anteroposterior view (A) and lateral view $(B)$, and e-Thrive MRI sequence with contrast agent $(C)$. Postoperative conventional $X$-rays 3 months after segmental resection $(D, E)$, and 7.5 years postoperatively $(F, G)$.

was detected in $52 \%$ of the junctions. One patient showed atrophy of the vascularized fibular graft following a perioperative complication. Concerning the fibular grafts, we found a mean hypertrophy rate of $47 \%$ at the proximal osteotomy sites and of $32 \%$ at the distal sites within 38 months. In iliac crest reconstructions, the mean hypertrophy rate of the graft was $27 \%$ at the proximal sites and $11 \%$ at the distal osteotomy sites. In the three patients in whom a medial femoral condyle graft was performed, no hypertrophy was observed radiographically. The grafts were completely integrated after a median of 34 months. The method of stabilization or graft length had no influence on hypertrophy. 
Table I. Patient characteristics.

\begin{tabular}{|c|c|c|c|c|c|c|c|c|c|c|c|c|}
\hline Case & Gender & $\begin{array}{l}\text { Age } \\
\text { (year) }\end{array}$ & Diagnosis & Site & $\begin{array}{l}\text { Defect } \\
\text { length } \\
(\mathrm{cm})\end{array}$ & $\begin{array}{c}\text { Distant } \\
\text { metastases }\end{array}$ & $\begin{array}{c}\text { Neo-adjuvant } \\
\text { therapy }\end{array}$ & $\begin{array}{c}\text { Adjuvant } \\
\text { therapy }\end{array}$ & ECI & $\begin{array}{c}\text { Resection } \\
\text { margins }\end{array}$ & $\begin{array}{c}\text { Reconstruction } \\
\text { with } \\
\text { vascularized }\end{array}$ & $\begin{array}{c}\text { Graft } \\
\text { length } \\
(\mathrm{cm})\end{array}$ \\
\hline 1 & $\mathrm{~F}$ & 18 & Giant cell tumor & Tibia & 7 & No & No & No & No & R0 & Iliac crest & 7 \\
\hline 2 & M & 11 & Aneurysmal bone cyst & Femur & 6 & No & No & No & No & R0 & Iliac crest & 6 \\
\hline 3 & $\mathrm{~F}$ & 31 & Giant cell tumor & Radius & 4 & No & No & No & No & R0 & Iliac crest & 4 \\
\hline 4 & M & 12 & Osteosarcoma & Tibia & 3 & No & CTX & CTX & No & R0 & Iliac crest & 2.8 \\
\hline 5 & M & 15 & Chondroblastoma & Talus & 4 & No & No & No & No & R0 & Iliac crest & 5.0 \\
\hline 6 & $\mathrm{~F}$ & 10 & Osteosarcoma & Femur & 25 & No & CTX & CTX & No & R0 & Fibula & 25 \\
\hline 7 & M & 8 & Osteosarcoma & Femur & 16 & No & CTX & CTX & No & R0 & Fibula & 16.5 \\
\hline 8 & M & 3 & Ewing's Sarcoma & Femur & 10.5 & No & CTX & CTX & No & $\mathrm{R} 1$ & Fibula & 10 \\
\hline 9 & $\mathrm{~W}$ & 11 & Adamantinoma & Tibia & 15 & No & No & No & Yes & R0 & Fibula & 16 \\
\hline 10 & M & 39 & Ewing's Sarcoma & Tibia & 11 & No & CTX & CTX & Yes & R0 & Fibula & 12 \\
\hline 11 & M & 12 & Rhabdomyosarcoma & Tibia & 18 & No & CTX & CTX, RTX & Yes & R0 & Fibula & 21 \\
\hline 12 & M & 25 & Giant cell tumor & Radius & 10.5 & No & No & No & No & R0 & Fibula & 10 \\
\hline 13 & $\mathrm{~F}$ & 17 & Osteosarcoma & Femur & 28 & Yes & CTX & CTX & No & R0 & Fibula & 27.5 \\
\hline 14 & $\mathrm{~F}$ & 7 & Osteosarcoma & Tibia & 15.5 & No & CTX & CTX & No & R0 & Fibula & 15 \\
\hline 15 & M & 12 & Ewing's sarcoma & Tibia & 12 & No & CTX & CTX & Yes & R0 & Fibula & 13 \\
\hline 16 & $\mathrm{~F}$ & 23 & Adamantinoma & Tibia & 22.5 & No & No & No & Yes & R0 & Fibula & 24 \\
\hline 17 & $\mathrm{~F}$ & 6 & Ewing's sarcoma & Femur & 15 & No & CTX & CTX & No & R0 & Fibula & 15.5 \\
\hline 18 & M & 37 & Ewing's sarcoma & Femur & 19.5 & Yes & CTX & CTX & Yes & R0 & Fibula & 19.5 \\
\hline 19 & $\mathrm{~F}$ & 15 & Ewing's sarcoma & Femur & 25 & No & CTX & CTX & No & R0 & Fibula & 25 \\
\hline 20 & $\mathrm{~F}$ & 5 & Ewing's sarcoma & Femur & 13 & No & CTX & CTX & No & Ro & Fibula & 13 \\
\hline 21 & M & 11 & Osteosarcoma & Humerus & 7 & No & CTX & CTX & No & R0 & Fibula & 8 \\
\hline 22 & M & 38 & Chondrosarcoma & Humerus & 8 & No & No & No & No & R0 & Fibula & 13 \\
\hline 23 & $\mathrm{~F}$ & 17 & Giant cell tumor & Talus & & No & No & No & No & R0 & $\begin{array}{l}\text { Medial femoral } \\
\text { condyle }\end{array}$ & 2 \\
\hline 24 & M & 20 & Chondroblastoma & Talus & 2 & No & No & No & No & R0 & $\begin{array}{l}\text { Medial femoral } \\
\text { condyle }\end{array}$ & 2 \\
\hline 25 & M & 33 & Chondroblastoma & Talus & 2 & No & No & No & No & R0 & $\begin{array}{l}\text { Medial femoral } \\
\text { condyle }\end{array}$ & 2 \\
\hline
\end{tabular}

CTX: Chemotherapy; RTX: radiotherapy; ECI: extracorporeal irradiation; M: male; F: female.

Functional outcome. We evaluated the functional outcomes of the 21 patients in which bone union was achieved using the MSTS score (18). The mean (SD) functional index was $86.7 \%( \pm 13)($ range $=57-100 \%)$ in the lower extremities and $84.4 \%( \pm 11)($ range $=76-97 \%)$ in the upper extremities. There was no statistically significant correlation between the MSTS score and the type of donor graft (Fibula $v s$. iliac crest $v s$. medial femoral condyle, $p=0.171)$.

Complications. Postoperative complications requiring surgical intervention were grouped into six categories based on the classification system by Henderson et al. (19) (Table II). Complication rates were highest in the fibular group. There were five cases of fracture of the transferred fibular grafts. One patient was asymptomatic and identified retrospectively during the oncological follow-up appointment and healed without intervention (case 14). Re-osteosynthesis was performed in two patients (cases 6,11 ), while one patient required plating and iliac bone grafting to promote union (case 7). One patient was treated conservatively (case
Table II. Postoperative complications according to Henderson classification.

\begin{tabular}{ll}
\hline Adverse events $(\mathrm{n}=25)$ & $\mathrm{n}(\%)$ \\
\hline 1. Soft-tissue failure & $1(4 \%)$ \\
2. Graft-host nonunion & $1(4 \%)$ \\
3. Structural failure & $7(28 \%)$ \\
4. Infection & $2(8 \%)$ \\
5. Tumor progression & $4(16 \%)$ \\
6. Pediatric failures & $3(12 \%)$ \\
\hline
\end{tabular}

21). Two further grafts fractured beneath fixation, necessitating intramedullary nailing (cases 18, 19).

Deep infection was observed in two patients. There was one case of staphylococcus capitis infection following screw perforation (case 16). Screw removal was performed, and the patient was also treated with intravenous culture specific antibiotics for two weeks and oral antibiotics for three months 
thereafter. One patient had a traumatic wound dehiscence associated with plate exposure (case 15). Therefore, the plate was removed, an intramedullary nail was inserted, and the wound was closed with a local fasciocutaneous flap.

One patient, who received neoadjuvant percutaneous irradiation, showed delayed healing of the distal part of the surgical wound, which was treated with a local transposition flap (case 11). In addition, the same patient suffered a traumatic fracture of the proximal osteotomy site, and after re-osteosynthesis, a rotational flap was performed. There was also one case of occlusion of the popliteal artery $12 \mathrm{~h}$ after index surgery that required thrombectomy and saphenous vein grafting (case 15). The same patient sustained a compartment syndrome with painful neuropraxia of the $\mathrm{N}$. peroneus profundus $48 \mathrm{~h}$ after first revision surgery. In a second look, a partial necrosis of the tibialis anterior muscle was obvious, requiring further reconstruction with a fasciocutaneous flap.

A mean (SD) limb-length discrepancy of $8.3 \mathrm{~cm}( \pm 4.7)$ (range $=3-12 \mathrm{~cm}$ ) was observed in three patients, which was managed by intramedullary lengthening (cases $6,7,15)$. In total, four patients $(16 \%)$ developed local recurrence. One patient underwent disarticulation of the hip (case 8) and in one patient following medial femoral condyle bone grafting a talectomy was performed (case 23 ). In the remaining two patients a less aggressive revision surgery could be performed (cases 11, 22).

We found no complications related to the iliac crest grafts in this series.

One patient exhibited painful flexion contracture of the toes and required extensor tendon lengthening (case 13). We found no other complications from the donor site in this study.

\section{Discussion}

Microvascular bone transfer is a well-established reconstructive procedure for widespread bone sarcomas in which amputation may be the only alternative. The aim of this study was to examine and compare clinical outcomes of bone tumor patients who had undergone microsurgical bone transposition using the ipsilateral fibula, iliac crest, or medial femoral condyle by means of a quality outcome analysis comparing radiographic outcome in terms of consolidation and hypertrophy, functional as well as oncologic outcomes and local complications at the donor and recipient sites.

Since survival rates of patients with malignant bone tumors have improved, mostly due to therapeutic effects of multi-agent chemotherapy, reconstructive bone interventions have become increasingly important, providing oncologic safety in combination with functional and cosmetic satisfaction. There are several reconstructive options for bone tumor patients, and, depending on oncological guidelines, specialized centers should be able to provide individualized treatment modalities.

Tumor endoprosthetic reconstruction is a frequently used technique after bone tumor resection, particularly in elderly patients, allowing immediate full weight-bearing (13) . Longterm results, however, are associated with complications such as aseptic loosening and infections, which can subsequently require removal of the endoprosthesis or even amputation of the affected extremity $(13,14,20)$. Although also biologic reconstructions have been shown to be associated with high complications, such as fractures, infections, and non-union (20), we have shown that the use of autologous bone grafts is feasible in children, adolescents, and young adults, with good prognosis $(8,9)$. In this study, we have compared three types of vascularized bone grafts. Initially, we hypothesized a correlation between complexity of graft dissection and flap survival rates. In our series, we found no significant difference between the three groups with flap survival rates of $92 \%$ for the fibular group, $100 \%$ for the iliac crest group, and $96 \%$ for the medial femoral condyle bone graft group.

In cases of diaphyseal tumors at the tibia, we used extracorporal irradiation and reimplanted the irradiated graft with a vascularized fibula. The related surgical technique was described by Krieg et al. in 2019 (21). In general, reconstruction of the tibia is challenging due to the poor vascular supply at the distal third, and the fact that malignant or intermediate tumors at the tibia usually follow chemotherapy. An excellent technique was described by Capanna et al., that combines an allograft with a vascularized fibular graft. The allograft ensures biomechanical stability, while the vascularized fibula provides union and hypertrophies within the allograft over time (22). Disadvantages of this technique are the long operating time (mean $8.5 \mathrm{~h}$ ), donor site morbidity and long time to full weight-bearing (mean 21.4 months after surgery) (22). Using extracorporal irradiation, on the other hand, allows biological reconstruction with the potential for long-term survival $(23,24)$. Operating time is much shorter and reimplantation spares the purchase of an allograft. Beside the perfect anatomical match of the irradiated graft, the vascularized fibula improves blood supply and thereby promotes union at the osteotomy sites (25).

In terms of radiographic outcomes of the vascularized grafts, bony union was observed in 86 to $92 \%$ of cases after a mean time of 4.5 to 12 months in previous studies $(10,12$, 26). In our data analysis, overall bony union of the fibular grafts was primarily achieved in $86 \%$ at the proximal osteotomy sites after a median time of 5 months, and in $64 \%$ at the distal osteotomy sites after a median of 6 months. However, delayed union occurred in the remaining distal junctions, and healed after a median of 18 months. Further, in our series, all patients with delayed union received either radio- or chemotherapy, which is supposed to be correlated with a detrimental effect on bony union. An anatomic factor 
that also determines the delayed rate of union is the poor vascular supply at the distal part of long bones, which is well described in the literature (27). Therefore, according to our experience, the distal osteotomy sites of diaphyseal reconstructions, need more time to union.

With a preserved vascular supply, bone grafts have the ability to hypertrophy, a remodeling process that has been proposed to enhance the mechanical strength of the grafts, and to reduce possible graft complications such as fatigue fracture and graft non-union. Several factors have been discussed to influence hypertrophy including mechanical loading $(28,29)$, increased graft vascularity $(17,29)$ and age of the patients $(29,30)$. We found biological activity in $70 \%$ of graft junctions. According to the standards described by De Boer and Wood (17), significant hypertrophy of more than $20 \%$ was observed in $52 \%$ of our patients. Our results are in line with previously published data, demonstrating that hypertrophy appears to be more common in young patients and in lower extremities, probably due to higher level of functional activity postoperatively $(10,17)$. In our series, most patients were able to regain full weight-bearing after bone union was achieved, and in the presence of mechanical loading through the recipient bone, significant hypertrophy was detected.

In our study, functional outcomes, reflected as the MSTS score, were highly satisfactory, with an average score of $86.7 \%$ in lower and $84.4 \%$ in upper extremities; these results fall within previously described MSTS scores ranging between $78 \%$ and $92 \%$ for vascularized autografts $(9,15,31)$.

Postoperative complications have become a major hurdle for the surgical decision-making process, and with progressive indications for bone reconstructions, it has increasingly become important to outline these complication rates. In our data, there were low complications in iiliac crest and medial femoral condyle reconstructions, however, various postoperative complications occurred in $48 \%$ of patients in the fibular group. Vascularized fibular graft technique encompasses extensive bone removal of up to 30 $\mathrm{cm}$ with the added difficulties of reconstruction and in case of segmental defects there are two sites of potential nonunion. Fatigue fracture was the most common complication in the fibular group and occurred in $28 \%$ of cases, that is in line with previously published data (32). Two grafts fractured beneath fixation that correlates with an increased likelihood of structural failure (32). Leg-length discrepancy was noted in 3 patients and was most likely attributed to the preceding fracture of the fibular graft and non-union in one case. The infection rate was only $8 \%$ in our cohort. Low et al. have shown that infections are well managed with viable blood supply of the grafts by local debridement and systemic antibiotics, which could also be confirmed by our two cases (33). We had one case with arterial thrombosis of an anastomosed vessel $12 \mathrm{~h}$ after index surgery, which stresses the importance of monitoring graft viability in the immediate postoperative period to prevent further complications.

Donor site complication varies between 7 and $35 \%$ in the literature and include ankle instability, various local muscular problems, sensory deficit and compartment syndrome $(12,34,35)$. In our data, donor-site complications were rather rare $(4 \%)$ and of the three different donor sites the only complication was painful flexion contracture of the toes related to a fibula donor site. However, donor-site morbidity does not appear to differ significantly between the three groups. Most of our patients were not bothered by motor weakness, numbness, or scar appearance.

Overall, vascularized bone grafting is associated with significant complication risks that surgeons need to be aware of. Nevertheless, we could show that this reconstructive approach offers substantial benefits to bone tumor patients.

Our study has several limitations. It was a retrospective, single-center study, involving a small number of patients as well as an unequal distribution of patients in the three groups. Furthermore, the included study population was very heterogeneous, and no control group was included that was operated on with different reconstructive procedures.

In conclusion, our study shows that vascularized fibula, iliac crest, and medial femoral condyle bone grafts are reliable reconstructive options in patients following bone tumor resection at the extremities. As bone sarcomas most commonly affect young patients, vascularized bone grafts have offered a reconstructive approach, maintaining long-term functionality and cosmetic satisfaction without compromising tumor recurrence outcomes. We demonstrated that this reconstructive approach is feasible with the concomitant use of chemo- and radiation therapy. While the vascularized fibula is a suitable graft in extensive defects of up to $30 \mathrm{~cm}$, the iliac crest and medial femoral condyle grafts both offer mechanical strength nearby joints and have overall low complication rates.

\section{Conflicts of Interest}

The Authors declare that there are no conflicts of interest regarding the present study.

\section{Authors' Contributions}

AHK and MH performed all surgeries and designed the work. SMG collected the data, performed data analysis and wrote the manuscript. AHK, MH and CD critically reviewed the manuscript. SMG, AHK und MH finalized the manuscript.

\section{References}

1 Stiller CA, Trama A, Serraino D, Rossi S, Navarro C, Chirlaque MD, Casali PG and RARECARE Working Group: Descriptive epidemiology of sarcomas in Europe: report from the RARECARE project. Eur J Cancer 49(3): 684-695, 2013. PMID: 23079473. DOI: 10.1016/j.ejca.2012.09.011 
2 Stiller CA, Craft AW, Corazziari I and EUROCARE Working Group: Survival of children with bone sarcoma in Europe since 1978: results from the EUROCARE study. Eur J Cancer 37(6): 760-766, 2001. PMID: 11311651. DOI: 10.1016/s0959-8049(01) 00004-1

3 Eilber FR, Eckhardt $\mathrm{J}$ and Morton DL: Advances in the treatment of sarcomas of the extremity. Current status of limb salvage. Cancer 54(11 Suppl): 2695-2701, 1984. PMID: 63888 12. DOI: $10.1002 / 1097-0142(19841201) 54: 2+<2695::$ aid-cncr 2820541415>3.0.co;2-o

4 DiCaprio MR and Friedlaender GE: Malignant bone tumors: limb sparing versus amputation. J Am Acad Orthop Surg 11(1): 25-37, 2003. PMID: 12699369.

5 Mankin HJ, Gebhardt MC, Jennings LC, Springfield DS and Tomford WW: Long-term results of allograft replacement in the management of bone tumors. Clin Orthop Relat Res (324): 86-97, 1996. PMID: 8595781. DOI: 10.1097/00003086-199603000-00011

6 Brigman BE, Hornicek FJ, Gebhardt MC and Mankin HJ: Allografts about the knee in young patients with high-grade sarcoma. Clin Orthop Relat Res (421): 232-239, 2004. PMID: 15123953. DOI: 10.1097/01.blo.0000127132.12576.05

7 Rödl RW, Ozaki T, Hoffmann C, Böttner F, Lindner N and Winkelmann W: Osteoarticular allograft in surgery for highgrade malignant tumours of bone. J Bone Joint Surg Br 82(7): 1006-1010, 2000. PMID: 11041590. DOI: 10.1302/0301620x.82b7.10644

8 Krieg AH and Hefti F: Reconstruction with non-vascularised fibular grafts after resection of bone tumours. J Bone Joint Surg Br 89(2): 215-221, 2007. PMID: 17322438. DOI: 10.1302/0301620X.89B2.17686

9 Lenze U, Kasal S, Hefti F and Krieg AH: Non-vascularised fibula grafts for reconstruction of segmental and hemicortical bone defects following meta- /diaphyseal tumour resection at the extremities. BMC Musculoskelet Disord 18(1): 289, 2017. PMID: 28679368. DOI: 10.1186/s12891-017-1640-Z

10 Hsu RW, Wood MB, Sim FH and Chao EY: Free vascularised fibular grafting for reconstruction after tumour resection. J Bone Joint Surg Br 79(1): 36-42, 1997. PMID: 9020442. DOI: 10.1302/0301-620x.79b1.6818

11 Hilven PH, Bayliss L, Cosker T, Dijkstra PD, Jutte PC, Lahoda LU, Schaap GR, Bramer JA, van Drunen GK, Strackee SD, van Vooren J, Gibbons M, Giele H and van de Sande MA: The vascularised fibular graft for limb salvage after bone tumour surgery: a multicentre study. Bone Joint J 97-B(6): 853-861, 2015. PMID: 26033069. DOI: 10.1302/0301-620X.97B6.34692

12 Shea KG, Coleman DA, Scott SM, Coleman SS and Christianson M: Microvascularized free fibular grafts for reconstruction of skeletal defects after tumor resection. J Pediatr Orthop 17(4): 424-432, 1997. PMID: 9364376.

13 Sewell MD, Hanna SA, McGrath A, Aston WJ, Blunn GW, Pollock RC, Skinner JA, Cannon SR and Briggs TW: Intercalary diaphyseal endoprosthetic reconstruction for malignant tibial bone tumours. J Bone Joint Surg Br 93(8): 1111-1117, 2011. PMID: 21768638. DOI: 10.1302/0301-620X.93B8.25750

14 Aldlyami E, Abudu A, Grimer RJ, Carter SR and Tillman RM: Endoprosthetic replacement of diaphyseal bone defects. Longterm results. Int Orthop 29(1): 25-29, 2005. PMID: 15633063. DOI: $10.1007 /$ s00264-004-0614-6

15 Schuh R, Panotopoulos J, Puchner SE, Willegger M, Hobusch GM, Windhager R and Funovics PT: Vascularised or non- vascularised autologous fibular grafting for the reconstruction of a diaphyseal bone defect after resection of a musculoskeletal tumour. Bone Joint J 96-B(9): 1258-1263, 2014. PMID: 25183600. DOI: 10.1302/0301-620X.96B9.33230

16 Taylor GI, Miller GD and Ham FJ: The free vascularized bone graft. A clinical extension of microvascular techniques. Plast Reconstr Surg 55(5): 533-544, 1975. PMID: 1096183. DOI: 10.1097/00006534-197505000-00002

17 de Boer $\mathrm{HH}$ and Wood MB: Bone changes in the vascularised fibular graft. J Bone Joint Surg Br 71(3): 374-378, 1989. PMID: 2722923. DOI: 10.1302/0301-620X.71B3.2722923

18 Enneking WF, Dunham W, Gebhardt MC, Malawar M and Pritchard DJ: A system for the functional evaluation of reconstructive procedures after surgical treatment of tumors of the musculoskeletal system. Clin Orthop Relat Res (286): 241246, 1993. PMID: 8425352.

19 Henderson ER, O'Connor MI, Ruggieri P, Windhager R, Funovics PT, Gibbons CL, Guo W, Hornicek FJ, Temple HT and Letson GD: Classification of failure of limb salvage after reconstructive surgery for bone tumours: a modified system Including biological and expandable reconstructions. Bone Joint J 96-B(11): 1436-1440, 2014. PMID: 25371453. DOI: 10.1302/ 0301-620X.96B11.34747

20 Landau MJ, Badash I, Yin C, Alluri RK and Patel KM: Free vascularized fibula grafting in the operative treatment of malignant bone tumors of the upper extremity: A systematic review of outcomes and complications. J Surg Oncol 117(7): 1432-1439, 2018. PMID: 29513891. DOI: 10.1002/jso.25032

21 Krieg AH, Lenze U, Schultze L, Gross MW and Haug M: Extracorporeal irradiation and reimplantation of tumor-bearing bone segments following diaphyseal sarcoma resection at the tibia. Anticancer Res 39(4): 2015-2023, 2019. PMID: 30952745. DOI: 10.21873 /anticanres.13312

22 Capanna R, Campanacci DA, Belot N, Beltrami G, Manfrini M, Innocenti $\mathrm{M}$ and Ceruso $\mathrm{M}$ : A new reconstructive technique for intercalary defects of long bones: the association of massive allograft with vascularized fibular autograft. Long-term results and comparison with alternative techniques. Orthop Clin North Am 38(1): 51-60, vi, 2007. PMID: 17145294. DOI: 10.1016/ j.oc1.2006.10.008

23 Hong AM, Millington S, Ahern V, McCowage G, Boyle R, Tattersall M, Haydu L and Stalley PD: Limb preservation surgery with extracorporeal irradiation in the management of malignant bone tumor: the oncological outcomes of 101 patients. Ann Oncol 24(10): 2676-2680, 2013. PMID: 23852310. DOI: 10.1093/annonc/mdt252

24 Davidson AW, Hong A, McCarthy SW and Stalley PD: En-bloc resection, extracorporeal irradiation, and re-implantation in limb salvage for bony malignancies. J Bone Joint Surg Br 87(6): 851-857, 2005. PMID: 15911672. DOI: 10.1302/0301-620X.87B6.15950

25 Krieg AH, Davidson AW and Stalley PD: Intercalary femoral reconstruction with extracorporeal irradiated autogenous bone graft in limb-salvage surgery. J Bone Joint Surg Br 89(3): 366371, 2007. PMID: 17356151. DOI: 10.1302/0301$620 \mathrm{X} .89 \mathrm{~B} 3.18508$

26 El-Gammal TA, El-Sayed A and Kotb MM: Hypertrophy after free vascularized fibular transfer to the lower limb. Microsurgery 22(8): 367-370, 2002. PMID: 12497574. DOI: 10.1002/micr.10066

27 Phieffer LS and Goulet JA: Delayed unions of the tibia. Instr Course Lect 55: 389-401, 2006. PMID: 16958474. 
28 Jones HH, Priest JD, Hayes WC, Tichenor CC and Nagel DA: Humeral hypertrophy in response to exercise. J Bone Joint Surg Am 59(2): 204-208, 1977. PMID: 845205.

29 Fujimaki A and Suda H: Experimental study and clinical observations on hypertrophy of vascularized bone grafts. Microsurgery 15(10): 726-732, 1994. PMID: 7885220. DOI: 10.1002/micr.1920151012

30 Huang W: How does the age factor influence the hypertrophy of vascularized bone grafts? An experimental study. J Nara Med Assoc 39: 756-772, 1988.

31 Hariri A, Mascard E, Atlan F, Germain MA, Heming N, Dubousset JF and Wicart P: Free vascularised fibular graft for reconstruction of defects of the lower limb after resection of tumour. J Bone Joint Surg Br 92(11): 1574-1579, 2010. PMID: 21037355. DOI: 10.1302/0301-620X.92B11.23832

32 de Boer HH, Wood MB and Hermans J: Reconstruction of large skeletal defects by vascularized fibula transfer. Factors that influenced the outcome of union in 62 cases. Int Orthop 14(2): 121-128, 1990. PMID: 2373557. DOI: 10.1007/BF00180115
33 Low CK, Pho RW, Kour AK, Satku K and Kumar VP: Infection of vascularized fibular grafts. Clin Orthop Relat Res (323): 163172, 1996. PMID: 8625574. DOI: 10.1097/00003086-1996020 00-00022

34 Weiland AJ: Current concepts review: vascularized free bone transplants. J Bone Joint Surg Am 63(1): 166-169, 1981. PMID: 7005238.

35 Minami A, Kasashima T, Iwasaki N, Kato H and Kaneda K: Vascularised fibular grafts. An experience of 102 patients. J Bone Joint Surg Br 82(7): 1022-1025, 2000. PMID: 11041594. DOI: $10.1302 / 0301-620 x .82 b 7.10332$

Received July 25, 2021

Revised August 8, 2021

Accepted August 9, 2021 